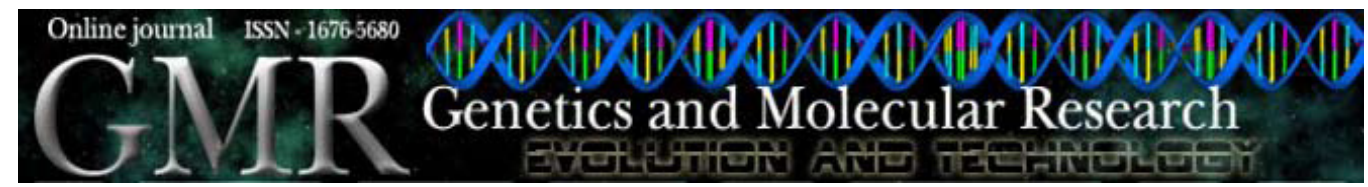

Case Report

\title{
MOMO syndrome associated with autism: a case report
}

\author{
C.T. Giunco ${ }^{1}$, D. Moretti-Ferreira ${ }^{2}$, A.E. Silva ${ }^{1}$, S.S. Rocha ${ }^{3}$ and \\ A.C. Fett-Conte ${ }^{4}$ \\ ${ }^{1}$ Departamento de Biologia, Instituto de Biociências, \\ Letras e Ciências Exatas, Universidade Estadual Paulista \\ "Júlio de Mesquita Filho", Campus de São José do Rio Preto, \\ São José do Rio Preto, SP, Brasil \\ ${ }^{2}$ Departamento de Genética, Instituto de Biociências de Botucatu, \\ Universidade Estadual Paulista "Júlio de Mesquita Filho", \\ Campus de Botucatu, Botucatu, SP, Brasil \\ ${ }^{3}$ Setor de Psiquiatria, Escola Municipal do Autista, \\ São José do Rio Preto, SP, Brasil \\ ${ }^{4}$ Departamento de Biologia Molecular, \\ Faculdade de Medicina de São José do Rio Preto, \\ São José do Rio Preto, SP, Brasil \\ Corresponding author: A.C. Fett-Conte \\ E-mail: genetica@famerp.br
}

Genet. Mol. Res. 7 (4): 1223-1225 (2008)

Received September 4, 2008

Accepted October 1, 2008

Published November 4, 2008

ABSTRACT. This is a case report of macrosomia, obesity, macrocephaly and ocular abnormalities (MOMO syndrome) associated with autism. Studies on genetic or environmental syndromes associated with autism can provide genetic markers or uncover relevant events, and are very important for the definition of autism subgroups in future molecular research.

Key words: Autism; Pervasive developmental disorders; MOMO syndrome 
MOMO syndrome is an extremely rare genetic disorder. The name is an acronym of the four primary aspects of the disorder: macrosomia, obesity, macrocephaly and ocular abnormalities (OMIM 157980). First described in two unrelated patients in 1993 by Moretti-Ferreira et al., it was suggested to be due to an autosomal dominant mutation. MOMO syndrome is considered to be a multisystemic genetic disease, and is associated with obesity. It is a syndrome of unknown etiology (Goldstone and Beales, 2008) and has never been described in association with autism.

The two cases described to date had behavioral disorders (aggressiveness, selfmutilation and excessive shyness) and mental retardation. In 2000, Zannolli et al. reported a possible third case in a patient with mild mental retardation and several characteristics of MOMO, but short stature. Given that macrosomy is one of the four major characteristics of this condition, the diagnosis of MOMO syndrome remains questionable in this case.

Autism is an emotional and cognitive developmental disorder that is characterized by impaired development in the areas of communication, social interaction and behavior (Tarelho and Assumpção Jr., 2007). A large number of genetic and chromosomal diseases have been associated with autism. The most frequently reported are fragile $\mathrm{X}$ syndrome and tuberous sclerosis. Associations with Down, Williams, Prader Willi, Angelman, and Aarskog syndromes, among others, have also been reported (Cohen et al., 2005; Greydanus and Pratt, 2005; Zafeiriou et al., 2007; Aitken, 2008). However, the etiologic links within these diseases have not yet been elucidated, and many questions about these associations with autism remain unanswered.

Our patient (Figure 1) is a sporadic case, the oldest sibling of a family with normal children born to healthy non-sanguineous parents. His birth weight was $3900 \mathrm{~g}$ (75th centile) and length was $50 \mathrm{~cm}$ (50th centile). Gestation was uneventful and delivery was at full-term by cesarean section.

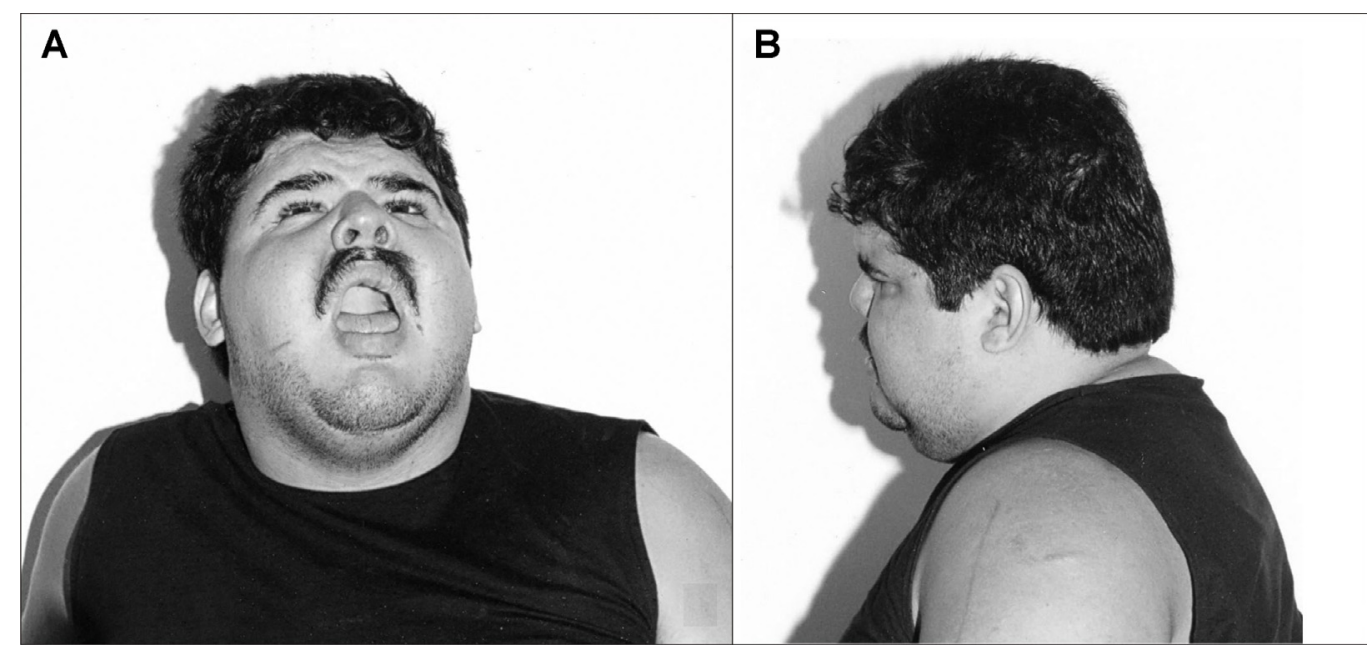

Figure 1. Frontal (A) and lateral (B) view of patient with MOMO syndrome and autism. 
The individual has mental retardation and has had epileptic seizures since the age of 11 months. He was diagnosed with autism when he was two years old and still exhibits all characteristics of the classic disease (APA, 1994), including deficits in reciprocal social interactions and communication (speech and language), stereotyped behavior and restricted interests and activities.

At the age of 29 years old, MOMO syndrome was detected during a clinical examination. The patient exhibited obesity, macrosomia ( $>98$ th centile), macrocephaly, OCP in the 98th centile, short neck, downward slanting palpebral fissures, microphthalmy, nystagmus, convergent strabismus, ocular hypertelorism, large nose with broad nasal root, macroglossia, high palate, large hands and feet (98th percentile), and psychomotor delay. At that time, an electroencephalogram revealed diffuse disorganization of brain activity. Routine hormone and heart tests were normal. The behavioral manifestations included lack of reciprocal social interactions, impairment in the use of eye-to-eye gaze, restricted interest and activities, aggressive, repetitive and stereotyped behavior, absence of verbal communication, and inflexible adherence to routines.

The karyotype was normal (46,XY), and molecular cytogenetics (fluorescence in situ hybridization, FISH) for the 7q31-q33 and 15q11-q13 regions, as well as molecular analysis of the FMR-1 gene by Southern blot revealed no alterations.

These findings suggest that this is probably the fourth case of MOMO syndrome described and the first one associated with autism. Studies on genetic or environmental syndromes associated with autism can provide genetic markers or uncover very relevant events, and are very important for the definition of autism subgroups in future molecular research.

\section{ACKNOWLEDGMENTS}

The authors wish to thank David Andrew Hewitt for the English revision and FAPESP (Fundação de Amparo à Pesquisa do Estado de São Paulo) for financial support.

\section{REFERENCES}

Aitken KJ (2008). Intersubjectivity, affective neuroscience, and the neurobiology of autistic spectrum disorders: a systematic review. Keio J. Med. 57: 15-36.

APA (American Psychiatric Association) (1994). DSM-IV - Diagnostic and Statistical Manual of Mental Retardation. 4th edn. American Psychiatric Press, Washington.

Cohen D, Pichard N, Tordjman S, Baumann C, et al. (2005). Specific genetic disorders and autism: clinical contribution towards their identification. J. Autism Dev. Disord. 35: 103-116.

Goldstone AP and Beales PL (2008). Genetic obesity syndromes. Front Horm. Res. 36: 37-60.

Greydanus DE and Pratt HD (2005). Syndromes and disorders associated with mental retardation. Indian J. Pediatr. 72: 859-864.

Moretti-Ferreira D, Koiffmann CP, Listik M, Setian N, et al. (1993). Macrosomia, obesity, macrocephaly and ocular abnormalities (MOMO syndrome) in two unrelated patients: delineation of a newly recognized overgrowth syndrome. Am. J. Med. Genet. 46: 555-558.

Tarelho LG and Assumpção FB Jr (2007). A case of pervasive developmental disorder with chromosomal translocation 1-4. Arq. Neuropsiquiatr. 65: 153-156.

Zafeiriou DI, Ververi A and Vargiami E (2007). Childhood autism and associated comorbidities. Brain Dev. 29: 257-272.

Zannolli R, Mostardini R, Hadjistilianou T, Rosi A, et al. (2000). MOMO syndrome: a possible third case. Clin. Dysmorphol. 9: 281-284. 